\title{
Brain-Derived Neurotrophic Factor Controls Activity-Dependent Maturation of CA1 Synapses by Downregulating Tonic Activation of Presynaptic Kainate Receptors
}

\author{
Marko Sallert, ${ }^{1,2}$ Tomi Rantamäki, ${ }^{1}$ Aino Vesikansa, ${ }^{1,2}$ Heidi Anthoni, ${ }^{1}$ Kirsi Harju, ${ }^{3}$ Jari Yli-Kauhaluoma, ${ }^{3}$ \\ Tomi Taira, ${ }^{1,2}$ Eero Castren, ${ }^{1}$ and Sari E. Lauri ${ }^{1,2}$ \\ ${ }^{1}$ Neuroscience Center, ${ }^{2}$ Division of Physiology, Department of Biological and Environmental Sciences, and ${ }^{3}$ Division of Pharmaceutical Chemistry, Faculty \\ of Pharmacy, University of Helsinki, FI-00014 Helsinki, Finland
}

Immature hippocampal synapses express presynaptic kainate receptors (KARs), which tonically inhibit glutamate release. Presynaptic maturation involves activity-dependent downregulation of the tonic KAR activity and consequent increase in release probability; however, the molecular mechanisms underlying this developmental process are unknown. Here, we have investigated whether brain derived neurotrophic factor (BDNF), a secreted protein implicated in developmental plasticity in several areas of the brain, controls presynaptic maturation by regulating KARs.

Application of BDNF in neonate hippocampal slices resulted in increase in synaptic transmission that fully occluded the immaturetype KAR activity in area CA1. Conversely, genetic ablation of BDNF was associated with delayed synaptic maturation and persistent presynaptic KAR activity, suggesting a role for endogenous BDNF in the developmental regulation of KAR function. In addition, our data suggests a critical role for BDNF TrkB signaling in fast activity-dependent regulation of KARs. Selective acute inhibition of TrkB receptors using a chemical-genetic approach prevented rapid change in synapse dynamics and loss of tonic KAR activity that is typically seen in response to induction of LTP at immature synapses.

Together, these data show that BDNF-TrkB-dependent maturation of glutamatergic synapses is tightly associated with a loss of endogenous KAR activity. The coordinated action of these two receptor mechanisms has immediate physiological relevance in controlling presynaptic efficacy and transmission dynamics at CA3-CA1 synapses at a stage of development when functional contact already exists but transmission is weak.

\section{Introduction}

Formation of functional synapses during development is dependent on endogenous electrical activity of the neuronal networks (Feller, 1999; Zhang and Poo, 2001; Lauri et al., 2003). Neuronal activity is thought to either reinforce or weaken the nascent neuronal connections by using synaptic mechanisms similar to those regulating synaptic efficacy in the adult brain, namely long-term potentiation (LTP) and long-term depression (LTD), and thereby control selection of synaptic inputs to a given neuron. It is well established that Hebbian-type plasticity mechanisms can control the targeting and insertion of glutamate receptors to the postsynaptic density already at very early stages of synapse development (Molnar and Isaac, 2002; Collingridge et al., 2004; Kerchner and Nicoll, 2008; Hanse et al., 2009). However, the corresponding presynaptic processes controlling activity-dependent maturation of glutamate release machinery are less well characterized.

\footnotetext{
Received Feb. 3, 2009; revised June 23, 2009; accepted June 25, 2009.

This work was supported by the Academy of Finland, the Sigrid Juselius Foundation, and the University of Helsinki. We thank Eli Lilly for providing LY382884. Outi Nikkilä is acknowledged for excellent technical help.

Correspondence should be addressed to Sari Lauri, Neuroscience Center and Department of Bio- and Environmental Sciences/Physiology, P.0. Box 65 (Viikinkaari 1), University of Helsinki, FI-00014 Helsinki, Finland. E-mail: sari.lauri@helsinki.fi.

DOI:10.1523/JNEUROSCI.0560-09.2009

Copyright $\odot 2009$ Society for Neuroscience $\quad$ 0270-6474/09/2911294-10\$15.00/0
}

We recently described a novel mechanism by which endogenous activity of kainate-type glutamate receptors (KARs) regulates presynaptic function at immature hippocampal synapses (Lauri et al., 2005, 2006). The tonic KAR activity maintains a low glutamate release probability and renders the immature synapses in area CA1 to preferentially respond to high-frequency input, which represents the predominant mode of activity of CA3 neurons during early postnatal development (Palva et al., 2000). This immature-type, tonic KAR activity in CA3-CA1 is rapidly switched off in response to experimental induction of LTP and gradually lost in parallel with maturation of the circuitry (Lauri et al., 2005, 2006; Sallert et al., 2007). Similar activity-dependent and/or developmental regulation of KARs has also been described in other types of synapses (Kidd et al., 1999; Lauri et al., 2001; Park et al., 2006). However, the molecular signaling mechanisms controlling the switch from immature- to adult-type KAR function is not known.

Neurotrophic factors and in particular the brain derived neurotrophic factor (BDNF), represent attractive candidates coupling neuronal activity to presynaptic maturation. BDNF can be secreted in an activity-dependent manner and has been shown to promote quantal glutamate release (Poo, 2001; Tyler et al., 2002; Bramham and Messaoudi, 2005; Carvalho et al., 2008). The presynaptic action of BDNF supports induction of 
LTP in juvenile (Figurov et al., 1996; Gottschalk et al., 1998; Xu et al., 2000; Zakharenko et al., 2003; Gärtner et al., 2006) and neonatal hippocampal slices (Mohajerani et al., 2007) as well as in hippocampal cultures (Shen et al., 2006). Interestingly, the extent of BDNF-induced potentiation of glutamatergic transmission is inversely proportional to the initial synaptic strength and preferentially occurs at immature contacts in cell culture (Lessmann and Heumann, 1998; Berninger et al., 1999; Shen et al., 2006) and is attenuated with age in hippocampal slices (Gottschalk et al., 1998; Kramár et al., 2004), similarly to what has been described for endogenously active KARs (Lauri et al., 2006).

We have here investigated the possibility that BDNF via its TrkB receptor controls presynaptic maturation by regulating KAR function in the hippocampus. Our results show that exogenous BDNF can readily downregulate tonic activity of KARs. Furthermore, data from two different transgenic mouse models supports a key role for endogenous BDNF/TrkB signaling in controlling presynaptic KAR function during development and in response to induction of LTP at immature synapses.

\section{Materials and Methods}

Animals. C57BL/6 wild-type (WT), BDNF null mutant (purchased from The Jackson Laboratory) (Ernfors et al., 1994), and TrkB ${ }^{\text {F616A }}$ knock-in mice (kindly provided by Dr. David Ginty, Johns Hopkins University, Baltimore, MD) (Chen et al., 2005) were used in the experiments. As reported previously, most homozygote mutants lacking BDNF die within 2 weeks after birth, and display severe developmental deficits, e.g., in the control of breathing (Ernfors et al., 1994; Erickson et al., 1996). In TrkB ${ }^{\text {F616A }}$ mice, the phenylalanine 616 at the ATP binding pocket site of TrkB is mutated to alanine. This mutation renders the receptor susceptible to inhibition by low concentrations of general kinase inhibitors, such as 1NMPP1. This mouse model has been used previously in both in vitro and in vivo settings to shut down ligand-dependent TrkB receptor activity (Chen et al., 2005; Huang et al., 2008).

Slice preparation. Acute hippocampal slices were prepared from wildtype, $\operatorname{Trk} B^{F 616 A}$, and $B D N F^{-/-}$mice at postnatal day 4 (P4) to P16. Mice were rapidly decapitated, and the brains were placed in ice-cold dissection solution containing the following (in $\mathrm{mM}$ ): $124 \mathrm{NaCl}, 3 \mathrm{KCl}, 1.25$ $\mathrm{NaH}_{2} \mathrm{PO}_{4}, 10 \mathrm{MgSO}_{4}, 26 \mathrm{NaHCO}_{3}, 15$ D-glucose, and $1 \mathrm{CaCl}_{2}$ (bubbled with $5 \% \mathrm{CO}_{2} / 95 \% \mathrm{O}_{2}$ ). Transverse hippocampal slices (400 $\mu \mathrm{m}$ thick) were cut with a vibratome (Vibratome) and placed in a recovery chamber, submerged in solution containing the following (in $\mathrm{mM}$ ): $124 \mathrm{NaCl}$, $3 \mathrm{KCl}, 1.25 \mathrm{NaH}_{2} \mathrm{PO}_{4}, 4 \mathrm{MgSO}_{4}, 26 \mathrm{NaHCO}_{3}, 15 \mathrm{D}$-glucose, and $2 \mathrm{CaCl}_{2}$ ( $5 \% \mathrm{CO}_{2} / 95 \% \mathrm{O}_{2}$, at room temperature). To prevent recurrent excitation, the CA3 region of the slices was cut away in experiments in which evoked EPSCs were recorded. The slices were used $1-5 \mathrm{~h}$ after cutting, except for the experiments in which BDNF was used. For these experiments, after a $30 \mathrm{~min}$ recovery time, the slices were placed into Millicell-CM membrane filter (Millipore) with $1 \mathrm{ml}$ of artificial CSF (ACSF) containing (in mM): $124 \mathrm{NaCl}, 3 \mathrm{KCl}, 1.25 \mathrm{NaH}_{2} \mathrm{PO}_{4}, 1 \mathrm{MgSO}_{4}$, $26 \mathrm{NaHCO}_{3}, 15 \mathrm{D}$-glucose, and $2 \mathrm{CaCl}_{2}\left(5 \% \mathrm{CO}_{2} / 95 \% \mathrm{O}_{2}\right.$ with or without $\mathrm{BDNF}$ at $250 \mathrm{ng} / \mathrm{ml}$; provided by Peprotech). Before the slices were transferred into a $\mathrm{CO}_{2}$ incubator $\left(35^{\circ} \mathrm{C}\right.$ under $5 \% \mathrm{CO}_{2}$ in air) for $2-3 \mathrm{~h}$, a $10 \mu \mathrm{l}$ droplet of BDNF final dilution or ACSF was applied on top of each slice. In some experiments, 1NMPP1 (20 nM) was applied $30 \mathrm{~min}$ before administration of BDNF.

Synthetic compounds. 1-(1,1-Dimethylethyl)-3-(1-naphthalenylmethyl)-1 Hpyrazolo[3,4- $d$ ] pyrimidin-4-amine (1NMPP1) was prepared from 5-amino-1(1,1-dimethylethyl)-3-(1-naphthalenylmethyl)- $1 \mathrm{H}$-pyrazole-4-carbonitrile according to the literature (Hanefeld et al., 1996; Bishop et al., 1999) and was purified by $\mathrm{SiO}_{2}$ column chromatography (eluent toluene/ethyl acetate, $3: 1, R_{f}$ of 0.2 ). Yield was $1.02 \mathrm{~g}(43 \%)$, purity was $>98 \%$ (contains $\sim 1.5 \% \mathrm{CH}_{2} \mathrm{Cl}_{2}$ ), and melting point was $175-176^{\circ} \mathrm{C}$. ${ }^{1} \mathrm{H}$ nuclear magnetic resonance $(\mathrm{NMR})\left(300 \mathrm{MHz}, \mathrm{DMSO}-d_{6}\right) \delta$ (ppm) was as follows: $8.25(\mathrm{~s}, 1 \mathrm{H}), 8.19-8.22(\mathrm{~m}, 1 \mathrm{H}), 7.87-7.91(\mathrm{~m}, 1 \mathrm{H}), 7.81(\mathrm{~d}, J=8.4 \mathrm{~Hz}$,
$1 \mathrm{H}), 7.50-7.59(\mathrm{~m}, 2 \mathrm{H}), 7.39(\mathrm{dd}, J=8.1$ and $6.9 \mathrm{~Hz}, 1 \mathrm{H}), 7.20(\mathrm{dd}, J=$ 6.9 and $1.2 \mathrm{~Hz}, 1 \mathrm{H}), 4.92$ (broad s, $2 \mathrm{H}), 4.75(\mathrm{~s}, 2 \mathrm{H})$, and $1.84(\mathrm{~s}, 9 \mathrm{H}) .{ }^{13} \mathrm{C}$ $\mathrm{NMR}\left(75 \mathrm{MHz}, \mathrm{CDCl}_{3}\right) \delta(\mathrm{ppm})$ was as follows: 158.0, 155.0, 154.7, $140.9,134.3,134.2,132.2,129.2,128.5,126.9,126.5,126.1,125.9,123.8$, 101.5, 60.4, 33.0, and 29.6. Fourier transform infrared values $(\mathrm{KBr}$, $\mathrm{cm}^{-1}$ ) were $3484,3303,1591,1556$, and 1247 . Liquid chromatographymass spectrometry measurement showed $[\mathrm{M}+\mathrm{H}]^{+}$ion at the mass-tocharge ratio of 332. Elemental analysis for $\mathrm{C}_{20} \mathrm{H}_{21} \mathrm{~N}_{5}$ was as follows: calculated C, 72.48\%; H, 6.39\%; N, 21.13\%; found C, 71.25\%; H, 6.21\%; $\mathrm{N}, 20.87 \%$.

Western blotting. The time-dependent effect of BDNF on TrkB phosphorylation and the validity of $\operatorname{TrkB}^{\mathrm{F} 616 \mathrm{~A}}$ mouse model (Chen et al., 2005) in slice experiments were confirmed by Western blot. After incubation, the slices were spun down on the bottom of Eppendorf tubes, ACSF was removed, and the sample was immediately frozen in $\mathrm{N}_{2}$ and stored at $-80^{\circ} \mathrm{C}$ before additional processing. Next, the sample was homogenized in $30 \mu \mathrm{l}$ of cold NP++ lysis buffer (Rantamäki et al., 2007) and centrifuged $\left(16,100 \times g, 15 \mathrm{~min},+4^{\circ} \mathrm{C}\right)$, and the supernatant was collected. An equal amount of protein $(100 \mu \mathrm{g})$ was subjected to wheat germ agglutinin (WGA) (Triticum vulgaris; EY Laboratories) lectin precipitation $\left(25 \mu \mathrm{l}\right.$ of $50 \% \mathrm{WGA} / \mathrm{NP}++$ slurry; $2 \mathrm{~h}$ at $\left.+4^{\circ} \mathrm{C}\right)$, followed with washes with $\mathrm{NP}++$ buffer. Next the samples were run in $7.5 \%$ SDS-PAGE under reducing conditions and blotted to a polyvinylidene difluoride membrane. TrkB receptor tyrosine phosphorylation was detected by using a polyclonal antibody directed against the phospholipase $\mathrm{C} \gamma 1$ binding site of the receptor (Y816) $\left(1: 5000\right.$, overnight at $+4^{\circ} \mathrm{C}$ ) using a previously described protocol (Rantamäki et al., 2007).

Electrophysiology. Slices were transferred to a recording chamber in which they were kept submerged and continuously superfused $(1 \mathrm{ml} /$ min) with ACSF at $32^{\circ} \mathrm{C}$. Whole-cell voltage-clamp recordings (holding potential, $-70 \mathrm{mV}$ ) were performed from CAl pyramidal neurons according to standard techniques using a MultiClamp 700B or Axoclamp 200A amplifier (Molecular Devices). Pipette resistance was 4-5 M $\Omega$ when filled with intracellular solution containing the following (in $\mathrm{mM}$ ): $120 \mathrm{CsMeSO}_{4}$, 10 HEPES, 0.5 EGTA, 10 BAPTA, 4 Mg-ATP, $0.3 \mathrm{Na}$ GTP, 5 QX-314 [N-(2,6-dimethylphenylcarbamoylmethyl)triethylammonium chloride], and $8 \mathrm{NaCl}(285 \mathrm{mOsm}), \mathrm{pH}$ 7.2. High-resistance electrodes (12-14 M $\Omega$ ) [filled with $130 \mathrm{~mm} \mathrm{CsMeSO}_{4}, 10 \mathrm{~mm}$ HEPES, 0.5 mM EGTA, 5 mm QX-314, 8 mm NaCl, 280 mOsm, pH 7.2, and amphotericin $\mathrm{B}$ at $300 \mu \mathrm{g} / \mathrm{ml}$ (Sigma)] were used during perforated patchclamp recordings. Recordings were started when an access resistance was $<120 \mathrm{M} \Omega$. Series resistance was continuously monitored using a $50 \mathrm{~ms}$, $5 \mathrm{mV}$ hyperpolarizing pulse, and it was not allowed to change $>20 \%$ during the course of the whole-cell and perforated patch experiments. Evoked EPSCs (eEPSCs) were elicited by Schaffer collateral pathway stimulation and recorded from CA1 pyramidal neurons in the presence of blockers of $\mathrm{GABA}_{\mathrm{A}}, \mathrm{GABA}_{\mathrm{B}}$, and NMDA receptors [100 $\mu \mathrm{M}$ picrotoxin (PiTX), $1 \mu \mathrm{M}$ CGP55845 [(2S)-3-[(15)-1-(3,4-dichlorophenyl)ethyl] amino-2-hydroxypropyl)(phenylmethyl)phosphinic acid], and $50 \mu \mathrm{M}$ D-AP5, respectively], except for LTP experiments, in which only PiTX was included in the ACSF. Baseline stimulation frequency was $1 / 20 \mathrm{~s}$ for single shocks and $1 / 60 \mathrm{~s}$ for collection of the trains at $50 \mathrm{~Hz}$, and the intensity was adjusted to the minimum strength eliciting a stable response (with the exception of experiments in which input-output data was collected). LTP was induced by pairing postsynaptic depolarization $(-10 \mathrm{mV})$ to 10 brief high-frequency trains (five pulses at $50 \mathrm{~Hz}$ ) of afferent activation. Experiments in which no LTP was induced (EPSC amplitude $<120 \%$ of control, $\sim 20 \%$ of inputs) were excluded from the analysis. Spontaneous miniature EPSCs (mEPSCs) were recorded in the presence of TTX ( $1 \mu \mathrm{M})$, D-AP-5 (50 $\mu \mathrm{M})$, CGP55845 $(1 \mu \mathrm{M})$, and PiTX (100 $\mu \mathrm{M})$. Pharmacological compounds were from Tocris Biosciences, except for LY382884 (3S,4aR,6S,8aR)-6-(4carboxyphenyl)methyl-1,2,3,4,4a,5,6,7,8,8a-decahydroisoquinoline-3carboxylic acid (Eli Lilly \& Co.).

Data analysis. WinLTP-program (Anderson and Collingridge, 2007) or pClamp software (Molecular Devices) were used for data acquisition. Evoked synaptic responses were analyzed using the WinLTP program. The amplitude of the evoked synaptic responses was measured as the peak relative to the average baseline level $2-8 \mathrm{~ms}$ before the stimulation. Synaptic facilitation was characterized by using short bursts of high- 
frequency stimulation (five pulses at $50 \mathrm{~Hz}$ ), and at least five consecutive trials were averaged for the analysis. Synapses were considered facilitatory when amplitude ratio of fifth/first EPSC was $>1.5$. mEPSCs were analyzed with the template search algorithm in the Clampfit 9.2 program (Molecular Devices). All the detected events were verified visually, and events with amplitude less than two times the baseline rms noise level were rejected. For time course plots, detected events were calculated in $120 \mathrm{~s}$ or 240 bins. Data are presented as percentage from baseline level before drug application or induction of LTP (100\% indicates no change). All the pooled data are given as mean \pm SEM for the number of cells indicated. Statistical significance was evaluated using Student's twotailed $t$ test or two-way ANOVA. $p<0.05$ was considered as statistically significant.

\section{Results}

BDNF potentiates presynaptic function at immature CA3-CA1 synapses

BDNF has been shown previously to enhance the presynaptic efficacy at several synapses, including hippocampal glutamatergic terminals (Tyler et al., 2002). To test the effect of BDNF on transmission at immature CA1 synapses, hippocampal slices from 4- to 5-d-old mice were preincubated with BDNF $(250 \mathrm{ng} / \mathrm{ml})$ in parallel with control slices treated with vehicle only. BDNF treatment led to a robust phosphorylation of the TrkB neurotrophin receptor within $30 \mathrm{~min}$, confirming that BDNF was biologically active in our conditions (Fig. 1A). Properties of glutamatergic transmission were analyzed after 2-3 h BDNF treatment by whole-cell patch-clamp recordings from CA1 pyramidal neurons. The average frequency of mEPSCs was clearly higher in BDNFtreated slices $(18.1 \pm 2.6$ events $/ \mathrm{min} ; n=$ 20) compared with controls (10.2 \pm 2.1 events/min; $n=23$ ), whereas no differences in the amplitude (control, $17.4 \pm$ $1.7 \mathrm{pA}$; BDNF, $18.9 \pm 1.3 \mathrm{pA}$ ) or kinetics (decay time: control, $7.2 \pm 0.4 \mathrm{~ms}$ and BDNF, $7.5 \pm 0.4 \mathrm{~ms}$; rise time: control, $1.7 \pm 0.1 \mathrm{~ms}$ and BDNF, $1.7 \pm 0.1 \mathrm{~ms}$ ) of mEPSCs were detected (Fig. $1 B, C$ ). The efficacy and dynamic properties of transmission were further studied by recording evoked EPSCs. The average amplitude of the EPSC in response to afferent stimulation was higher in BDNF-treated slices $(n=8)$ compared with controls $(n=9$; $p<0.001$ ) (Fig. $1 D, E$ ), indicating that BDNF treatment enhanced synaptic efficacy. In addition, the threshold for evoking response was lower in BDNF-treated slices $(5.8 \pm 0.7 \mathrm{~V} ; n=13)$ compared with controls $(8.3 \pm 1.4 \mathrm{~V} ; n=17 ; p<0.05)$. The synaptic responses to short bursts
A

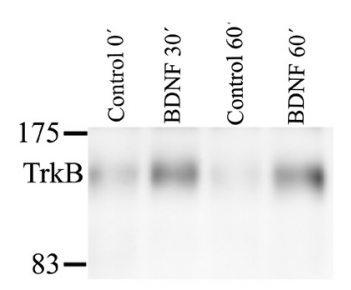

B

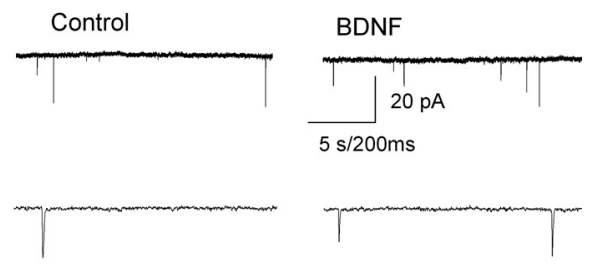

C

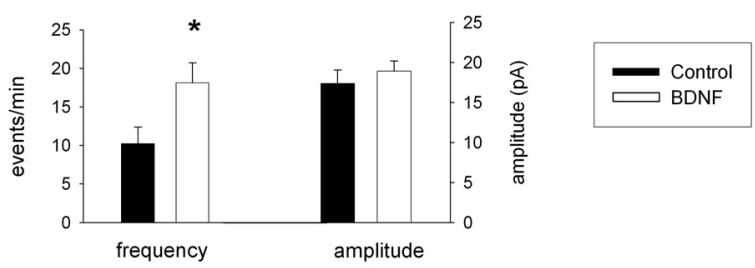

D

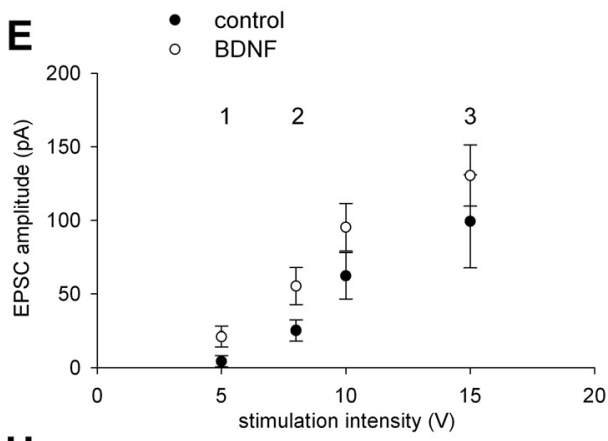

$\mathbf{F}$
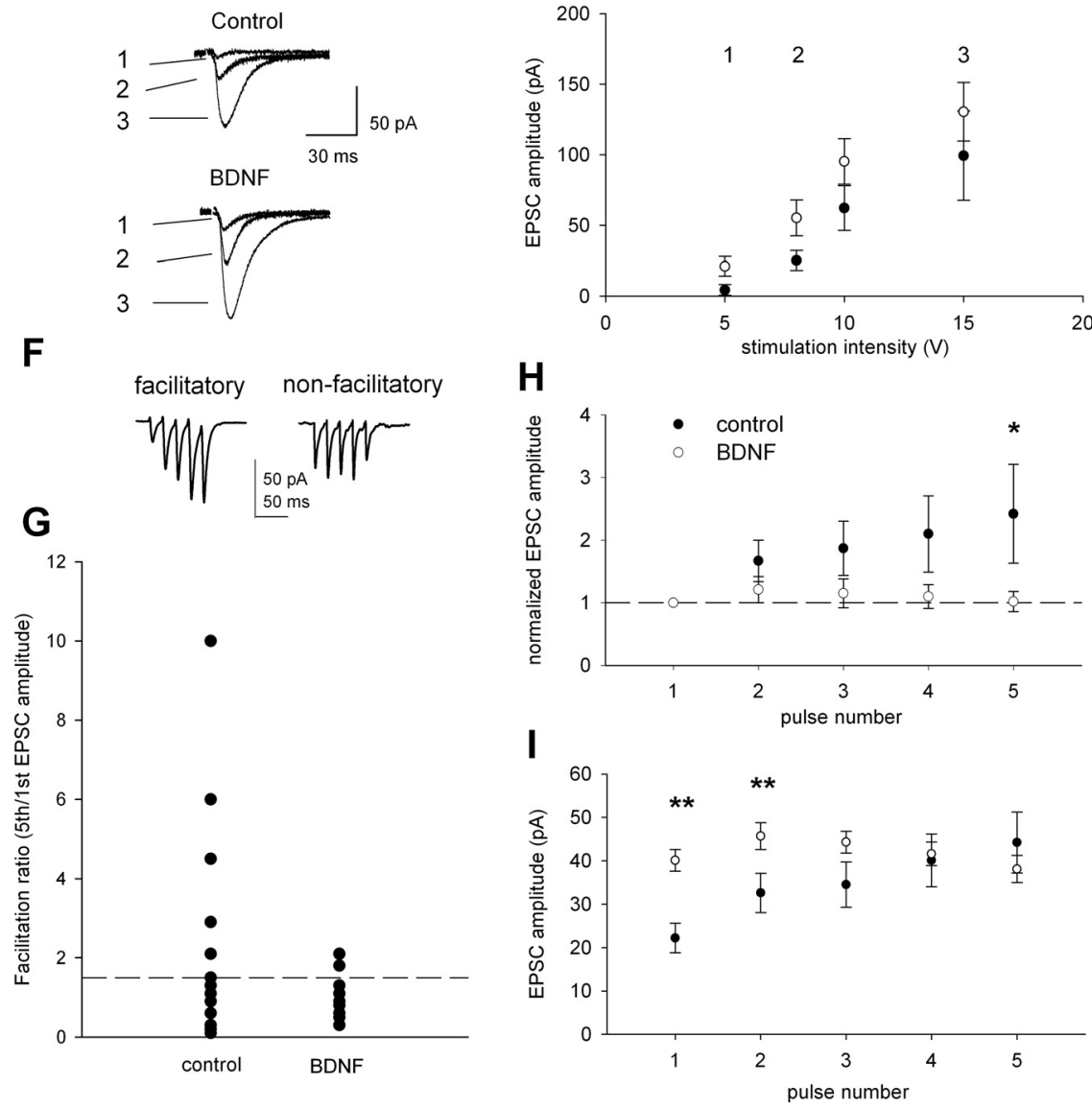

Figure 1. BDNF activates TrkB receptors and enhances presynaptic function in the area CA1 of newborn (P4-P5) mouse hippocampus. A, A Western blot showing robust phosphorylation of TrkB receptors in acute hippocampal slices in response to BDNF treatment $(250 \mathrm{ng} / \mathrm{ml}, 0-60 \mathrm{~min})$ but not in response to $60 \mathrm{~min}$ incubation with vehicle alone. $B$, Examples of recordings of mEPSCs in CA1 pyramidal neurons from control and BDNF-treated slices. C, Pooled data showing higher frequency but no differences in the amplitude of mEPSCs in BDNF-treated slices compared with controls (control, $n=23 ; \mathrm{BDNF}, n=20$ ). ${ }^{*} p<0.05$. $D$, Example traces of EPSCS evoked by three different stimulation voltages in control and BDNF-treated slices. $E$, Input- output curves showing that BDNF pretreatment significantly increased the amplitude of EPSCs (control, $n=9 ; \mathrm{BDNF}, n=8)$. $p<0.001$. $\boldsymbol{F}$, Example traces showing typical postsynaptic responses to short bursts of high-frequency afferent stimulation ( 5 pulses at $50 \mathrm{~Hz}$ ) at immature CA3-CA1 synapses. Input was considered facilitatory when amplitude ratio of fifth/first EPSC was >1.5. G, Synaptic facilitation ratio (fifth EPSC/first EPSC amplitude) at individual inputs in BDNF-treated and in control slices. BDNF pretreatment reduced the amount of facilitatory synapses compared with control (BDNF, 2 of 12 were facilitatory; in control, 6 of 13 ). $\boldsymbol{H}$, Averaged data on the effects of BDNF treatment on synapticfacilitation. The graph shows the amplitude of each EPSC in the train, normalized to the amplitude of the first EPSC in control versus BDNF-treated slices (control, $n=13 ;$ BDNF, $n=12$ ). ${ }^{*} p<0.05$. I, BDNF reduces facilitation by increasing the amplitude of the first eEPSC. The graph shows the same data as in $\boldsymbol{H}$ without normalization. ${ }^{* *} p<0.01$. 
A
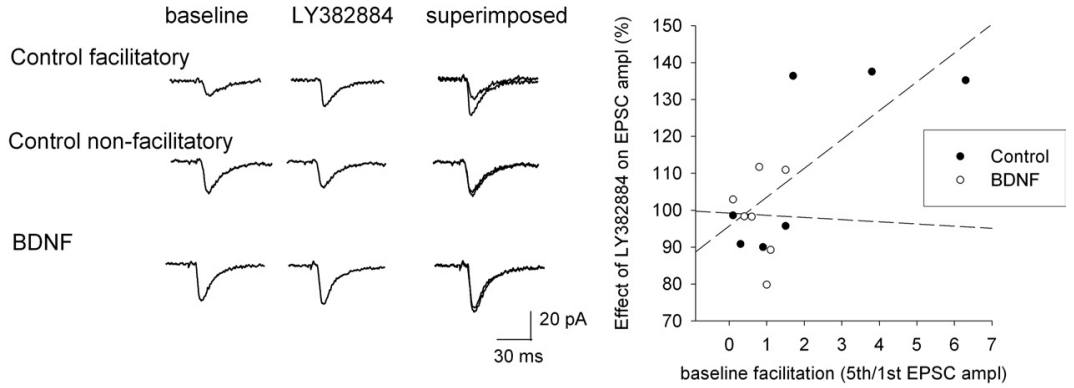

\section{B Control}
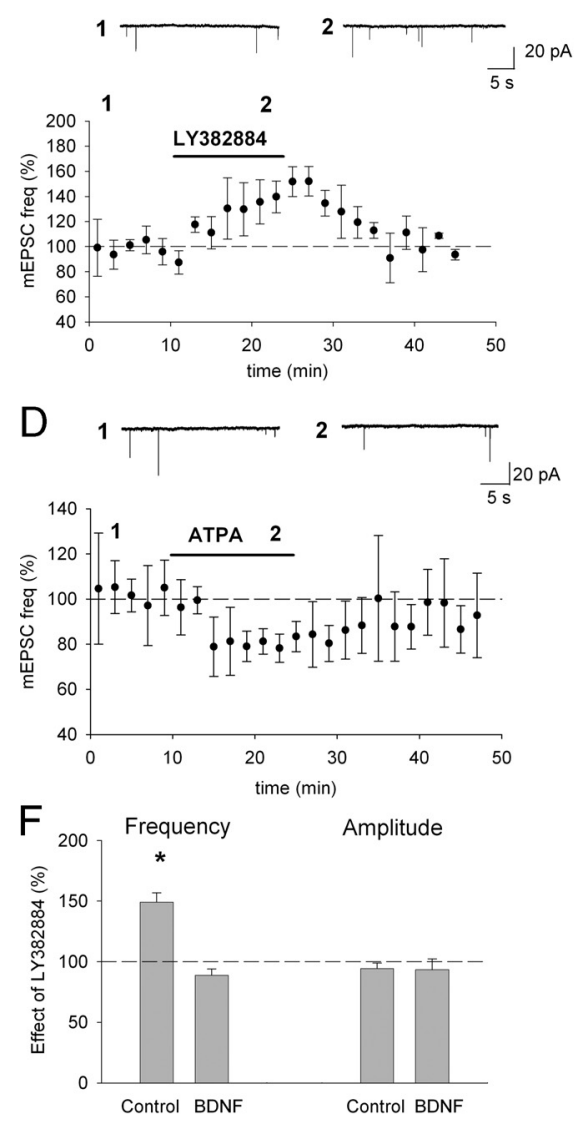

Figure 2. BDNF treatment fully abolishes immature-type KAR activity. $A$, The effect of LY382884 on evoked EPSC amplitude in control $(n=7)$ and BDNF-treated slices $(n=7)$. Example traces show superimposed EPSCs recorded before and 10 min after application of LY382884, in a facilitatory control input and in nonfacilitatory inputs in control and BDNF-treated slices. The graph shows the effect of LY382884 on EPSC amplitude against the level of facilitation (fifth/first EPSC amplitude in response to 5 pulses at $50 \mathrm{~Hz}$ stimulation) at individual experiments. In BDNF-treated slices, no facilitatory inputs were observed. $\boldsymbol{B}$, Tonic KAR activity in the control slices. Example traces from the time points indicated and averaged data $(n=6)$ showing the effect of LY382884 (10 $\mu \mathrm{M}$ ) on mEPSC frequency in control slices (P4-P5). mEPSCs were calculated in $120 \mathrm{~s}$ bins and normalized to the baseline level before application of LY382884. C, Corresponding data for BDNF-treated slices $(n=6) . \boldsymbol{D}, \boldsymbol{E}$, Example traces and pooled data showing that ATPA $(1 \mu \mathrm{M})$ decreases the frequency of mEPSCs in control slices $(n=5)$ but not in BDNF-treated slices $(n=5) . \boldsymbol{F}$, Summary data on the effect of LY382884 on mEPSC frequency and amplitude at control and BDNF-treated slices. ${ }^{*} p<0.05 . \mathbf{G}$, Summary data on the effect of ATPA on mEPSC frequency and amplitude at control and BDNF-treated slices. ${ }^{*} p<0.05$.

(five pulses) of high-frequency $(50 \mathrm{~Hz})$ stimulation in the control slices displayed large heterogeneity in short-term plasticity (Fig. $1 F, G)$, which is typical for immature CA3-CA1 synapses and reflects variability in the glutamate release probability within the synapse population (Hanse and Gustafsson, 2001; Lauri et al., 2006). Interestingly, after BDNF treatment, the facilitatory inputs representing the immature synapses with low initial release probability $\left(P_{\mathrm{r}}\right)$ were lost (Fig. $\left.1 G\right)$, and, on average, little or no shortterm plasticity in response to $50 \mathrm{~Hz}$ stimulation was detected (average ratio of fifth/first EPSC was $242 \pm 79$ and $102 \pm 16 \%$ in control and BDNF-treated slices) (Fig. $1 \mathrm{H}$ ). The loss of facilitation was attributable to increase in the amplitude of the first EPSC after BDNF treatment $(181 \pm 17 \%$ compared with control) (Fig. 1I). Together, these data suggest that, similar to results obtained in cultured hippocampal neurons (Lessmann and Heumann, 1998), BDNF treatment in neonate CA1 leads to increase in glutamate release probability preferentially at developing synapses with initially low $P_{\mathrm{r}}$.

\section{BDNF downregulates immature type presynaptic KAR activity}

To test whether BDNF was able to regulate KAR activity at CA3-CA1 synapses, we used KAR antagonist LY382884 $(10 \mu \mathrm{M})$, which has been shown previously to potentiate transmission selectively at immature synapses that express tonically active presynaptic KARs (Lauri et al., 2006) and are characterized with a facilitatory response to $50 \mathrm{~Hz}$ stimulation.

As expected, in control slices, LY382884 potentiated transmission selectively at facilitatory inputs (EPSC amplitude, $136 \pm 6 \%$ of control; $n=3$ ) but had no effect on transmission at nonfacilitatory inputs ( $94 \pm 2 \%$; $n=4)$. After BDNF treatment, none of the tested inputs were facilitatory, and LY382884 had no detectable effects on EPSC amplitude $(99 \pm 4 \% ; n=7)$ (Fig. 2A).

Because LY382884 has no effect on transmission at mature synapses, the magnitude of the effect of LY388284 on mEPSC frequency can be used as a tool to assess the presence of immature-type, tonic KAR activity in a synapse population. At control slices, application of LY382884 increased the frequency of mEPSCs to $149 \pm 8 \%(n=6)$ of the baseline level without affecting their amplitude $(93 \pm$ 9\%) (Fig. $2 B, F$ ). In BDNF-treated slices, however, LY382884 had no effect on mEPSCs or caused small reduction in their frequency $(89 \pm 5 \% ; n=6$ ) (Fig. $2 C, F)$. Because the baseline frequency of mEPSCs is higher after BDNF treatment, it is possible that the lack of effect of LY382884 is attributable to saturation of $P_{\mathrm{r}}$ rather than loss of tonic KARs activity. Therefore, we also tested the effect of KAR agonist $(R S)$-2-amino-3-(3-hydroxy-5- tertbutylisoxazol-4-yl)propanoic acid (ATPA), which at $1 \mu \mathrm{M}$ concentration causes a small but significant depression of mEPSC frequency in the immature but not 2-week-old CA1 (Lauri et al., 2006; Sallert et al., 2007). Consistently, in the control slices, mEPSC frequency decreased to $79 \pm$ $6 \%(n=5)$ of control, with no associated changes in amplitude $(99 \pm 2 \%)$, in response to ATPA application (Fig. 2D, G). In BDNFtreated slices, this effect was completely lost, and, if anything, ATPA resulted in a slight increase in the frequency of mEPSCs (113 $\pm 9 \%$; 
$n=5$ ) (Fig. 2E, $G$ ). Thus, in response to BDNF treatment, the immature-type presynaptic KAR activity is completely lost in parallel with the disappearance of inputs with a low glutamate release probability.

\section{Lack of endogenous BDNF perturbs} early functional maturation of CA3CA1 synapses and prevents the developmental switch in KAR function Given the strong effects of BDNF on presynaptic function and KAR activity at immature synapses, we next looked at the role of endogenous BDNF in the maturation of glutamatergic synapses using $B D N F^{-/-}$mice. The average mEPSC frequency in CA1 pyramidal neurons in the $\mathrm{BDNF}^{-/-}$mice $(4.5 \pm 1.8$ events $/ \mathrm{min}$; $n=12$ ) was significantly less compared with WT controls $(9.1 \pm 2.8 ; n=11)$ already at $\mathrm{P} 4$ (Fig. $3 A, B$ ). Both in the WT and $B D N F^{-1-}$, the average frequency of mEPSCs increased during the first postnatal week (59 and 53\% increase from P4 to $\mathrm{P} 7$ for WT and $B D N F^{-1-}$, respectively); however, mEPSC frequency remained lower in the $B D N F^{-1-}$ mice throughout the $10 \mathrm{~d}$ of life (Fig. $3 A, B$ ). In contrast, no significant differences in the mean amplitude of mEPSCs were detected between the genotypes at any developmental stage tested (Fig. $3 A, C$ ).

We next studied the tonic KAR activity in the $B D N F^{-/-}$mice by testing the sensitivity of transmission to KAR antagonist LY382884. In WT animals, the effect of LY382884 on mEPSC frequency was developmentally downregulated in parallel with maturation of the synapses, from $141 \pm 16 \%(n=7)$ at $\mathrm{P} 4-\mathrm{P} 5$ to $123 \pm 9 \%(n=15)$ at P7-P10 and to $97 \pm 5 \%(n=5)$ at P14-P16 (Fig. $4 A, B, C, F)$. In contrast, in the $B D N F^{-1-}$ mice, the KAR activity at P7-P10 remained in the same level as in $\mathrm{P} 4(140 \pm 12 \%, n=8$ at P4; $147 \pm$ $11 \%, n=16$ at P7-P10) (Fig. $4 D-F$ ). Thus, presynaptic maturation and the developmental downregulation of KAR activity does not occur or is significantly delayed in the absence of BDNF.

\section{Selective inhibition of TrkB signaling prevents rapid changes in synapse dynamics and in presynaptic KAR function in response to induction of LTP}

A rapid change in both dynamic properties of transmission as well as in tonic KAR activity can be seen in response to pairinginduced LTP at the low $P_{\mathrm{r}}$ facilitatory synapses in the neonate CA1 (Lauri et al., 2006). This mechanism is thought to mimic the activity-dependent maturation process that gradually occurs in the synapse population during development. Hence, we went on to test whether BDNF signaling is involved in the presynaptic changes associated with LTP at immature synapses. Because the glutamatergic transmission was severely perturbed in the $B D N F^{-/-}$mice, we here used another mouse model, TrkB ${ }^{\mathrm{F} 616 \mathrm{~A}}$, in which a single point mutation in the TrkB receptor renders it highly susceptible for inhibition by a chemical substance called 1NMPP1 (Chen et al., 2005). We first controlled that application of 1NMPP1 completely blocked BDNFinduced TrkB phosphorylation in hippocampal slices from P5
B
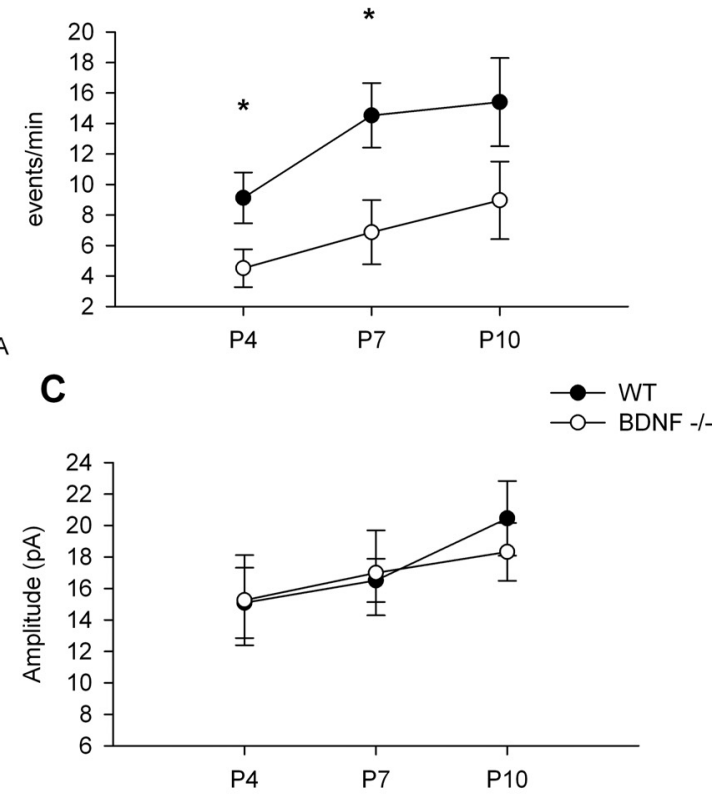
A

WT P4

baseline LY382884 washout
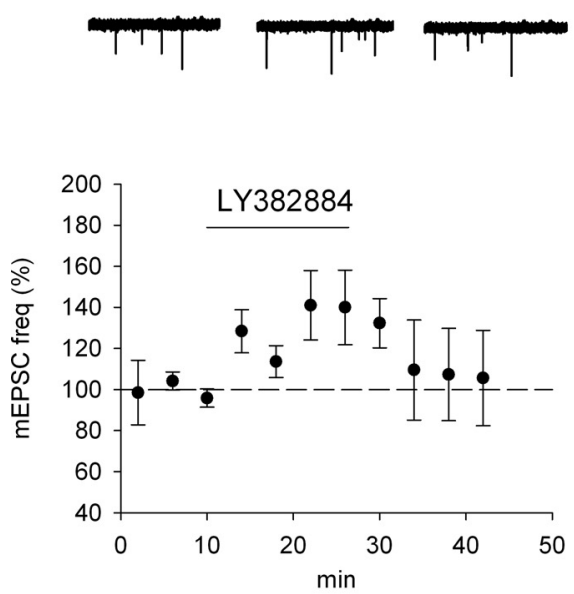

D

BDNF -/- P4
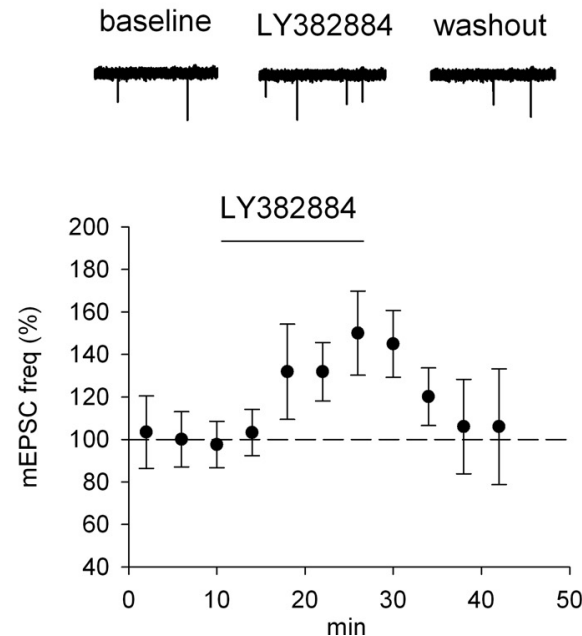

B WT P7-P10

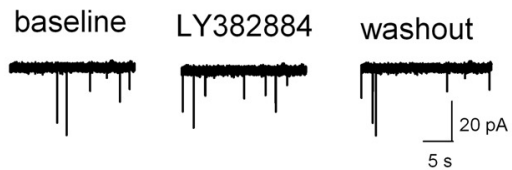

C WT P14-P16

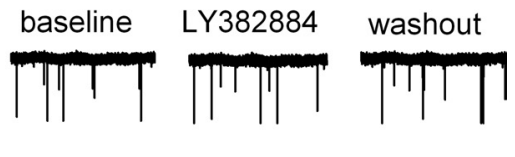

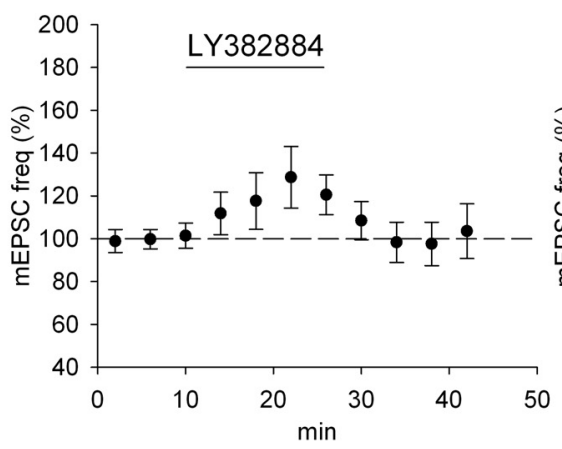

E

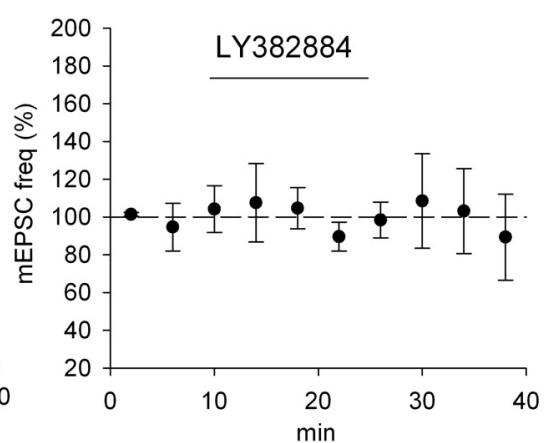

F
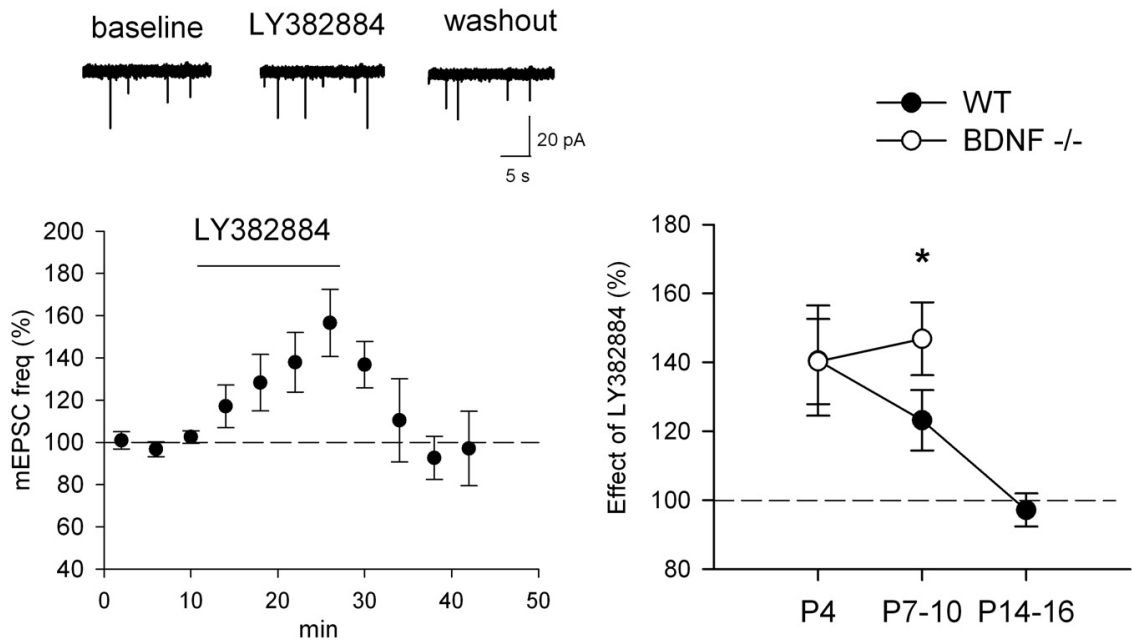

Figure 4. The immature-type, tonic KAR activity is persists during development in the absence of BDNF. $A-C$, Example traces and averaged data on the effect of $L Y 382884$ on mEPSC frequency in WT mice at P4 $(n=7), \mathrm{P} 7-\mathrm{P} 10(n=15)(\boldsymbol{B})$, and P14-P16 $(n=5)(\boldsymbol{C})$. mEPSCs were calculated in 240 s bins. $\boldsymbol{D}, \boldsymbol{E}$, Corresponding data for BDNF ${ }^{-/-}$mice at P4 $(n=8)$ and P7-P10 $(n=16)$. $\boldsymbol{F}$, Summary graph showing the developmental profile of the effect of LY382884 on mEPSC frequency in WT and BDNF ${ }^{-1-}$ mice. In the WT mice, the effect of LY382884 on mEPSC frequency is gradually downregulated during development and lost at P14. At BDNF ${ }^{-/-}$mice, the effect of LY382884 at P7 is retained at the same level as in P4. ${ }^{*} p<0.05$ between the genotypes.

application of LY382884 (Fig. 6A,B). However, LTP induction in the presence of 1NMPP1 was not associated with changes in short-term plasticity; in contrast to control conditions, the facilitatory inputs remained facilitatory after pairing (from $2.28 \pm 0.41$ to $2.15 \pm 0.42 ; n=9$ ), and this facilitation was completely blocked by application of LY382884 (from $2.15 \pm$ 0.42 to $1.16 \pm 0.23 ; n=9$ ) (Fig. $6 C$ ).

The loss of the tonic inhibition of glutamate release by KARs in response to pairing influences the level of LTP at the facilitatory inputs (Lauri et al., 2006). Consistently, pairing-induced potentiation at the subpopulation of facilitatory inputs was smaller in the presence of 1NMPP1 (179 $\pm 17 \% ; n=10)$ compared with control ( $192 \pm 16 \% ; n=11$; data not shown).

Thus, fast activity-dependent changes in synapse dynamics and in presynaptic KAR activity failed in the absence of TrkB signaling. These data strongly suggest that, although not necessary for pairing-induced synaptic potentiation per se, BDNF-
TrkB signaling is critical for the presynaptic alterations, including downregulation of KAR activity, that are typically associated with LTP at immature synapses.

\section{Discussion}

Although the mechanisms by which BNDF-TrkB-initiated signaling influence presynaptic function have been widely studied, little is known about how these mechanisms interact with the function of other presynaptic receptors. Our data describe a previously unexplored mechanism by which BDNF-TrkB signaling controls presynaptic efficacy by regulating the function of kainate receptors. By detailed characterization of the developmental effects of both exogenous and endogenous BDNF on glutamatergic transmission in hippocampal slices, we show that BDNFdependent synaptic maturation is tightly associated with a loss of endogenous activity of presynaptic KARs. Furthermore, our results show that the BDNF-TrkB signaling and the associated 
change in presynaptic KAR function is critical in controlling fast changes in synapse dynamics that rapidly occur at immature synapses in response to induction LTP.

\section{Presynaptic development, BDNF, and KARs}

The mechanisms by which BDNF regulates synaptic transmission depend on the type and developmental stage of the synapse and include direct and indirect effects on ion channel activity and on presynaptic release machinery (for review, see Poo, 2001; Tyler et al., 2002; Rose et al., 2004; Carvalho et al., 2008). At immature CA3-CA1 synapses, the predominant effect of BDNF application was to enhance glutamate release. Thus, in acute slices from 4- to 5-d-old mice, BDNF treatment resulted in a loss of synaptic facilitation as well as increase in the frequency, but no change in the amplitude or kinetics of mEPSCs. These functional changes can be fully explained by BDNFinduced increase in $P_{\mathrm{r}}$ at the developing synapses, a conclusion that is also supported by previous studies in the area CA1 (Tyler et al., 2001, 2006; Mohajerani et al., 2007). However, we cannot exclude the possibility that other mechanisms, for example, BDNF-dependent increase in the number of synapses, occur in parallel and contribute to the observed effects.

Glutamate release probability at central neurons can be rapidly and strongly regulated by presynaptic autoreceptors and heteroreceptors, including kainate receptors (Pinheiro and Mulle, 2008). At immature CA3-CA1 synapses, KAR activity tonically restrains presynaptic function (Lauri et al., 2006) and thus offers a potent target for regulation of synaptic efficacy. Interestingly, BDNF treatment fully occluded the mechanism by which KARs regulate mEPSCs at immature CA1 synapses. Therefore, $\mathrm{BDNF}$ acted on the undeveloped synapse population to mimic the developmental process of presynaptic maturation, in terms of increasing $P_{\mathrm{r}}$ and downregulating the KAR activity.

The link between BDNF, synaptic maturation, and KAR activity is further supported by delayed presynaptic development in BDNF knock-out mice. In the absence of BDNF, functional glutamatergic input to CA1 pyramidal neurons was severely impaired at all developmental stages tested during the first 2 postnatal weeks, observed as a lower mEPSC frequency in $B D N F^{-/-}$mice compared with WT controls. In both genotypes, the frequency of mEPSCs significantly increased from $\mathrm{P} 4$ to $\mathrm{P} 10$, indicating that functional glutamatergic input to CA1 was developmentally strengthened also in the absence of BDNF. However, in contrast to wild types, the CA1 synapses in the $B D N F^{-/-}$mice remained immature in terms of presynaptic KARs. Thus, in the absence of BDNF, the glutamatergic synapses failed to go through a process
C 1NMPP1
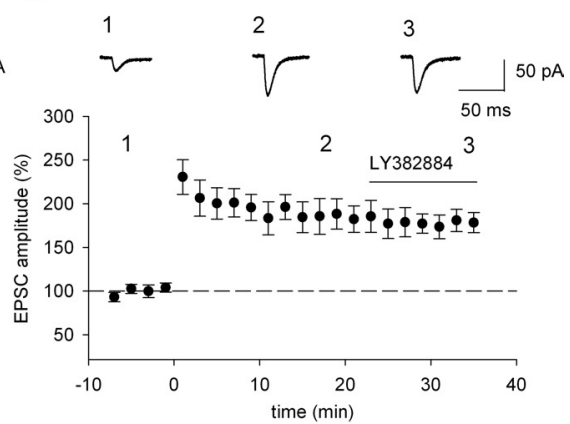

E

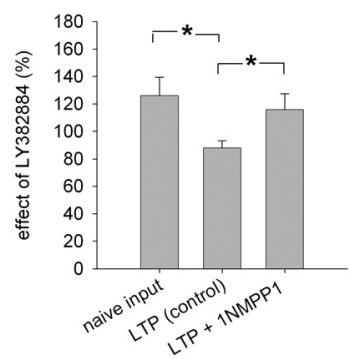

- LTP (control)

- LTP + 1NMPP1

Acute inhibition of TrkB has no effect on induction of LTP but prevents the associated loss of tonic KAR activity. , Western blot showing that phosphorylation of TrkB receptors in response to BDNF treatment $(250 \mathrm{ng} / \mathrm{ml}, 30 \mathrm{~min})$ of acute inpocampal slices from the TrkB ${ }^{\mathrm{F} 616 \mathrm{~A}}$ mice (P5) is fully prevented by 1NMPP1. $\boldsymbol{B}$, Averaged data and example traces from was applied 20 min after pairing to test tonic KAR activity. C, Corresponding data from recordings in the presence of graph on the effect of LY382884 on first EPSC amplitude against the baseline (before pairing) level of facilitation in indidua xperiments. Positive correlation between the effect of $L Y 382884$ and the baseline facilitation is seen at naive inputs $(n=12)$ but (LTP (control), $n=14$ ]. The correlation persists when LTP is induced in the resence of 1NMPP1 (LTP + 1NMPP1, $n=15$ ). $E$, Averaged data from the initially facilitatory inputs, showing that LY382884 increases EPSC amplitude at naive inputs $(n=7)$, and this effect is lost after LTP induction under control conditions [LTP (control), $n=9$ ] but not when LTP is induced in the presence of 1NMPP1 (LTP + 1NMPP1, $n=9$ ). ${ }^{*} p<0.05$.

of presynaptic maturation that involves downregulation of the endogenous KAR activity.

\section{Fast activity-dependent effects of TrkB signaling at immature synapses}

The proposed mechanism to explain the presynaptic actions of BDNF in the context of Hebbian-type plasticity involves its activity-dependent secretion and binding to presynaptic TrkB receptors, which initiate downstream signaling pathways to modulate glutamate release (Poo, 2001; Tyler et al., 2002). To test whether such mechanism could be involved in the developmental maturation of CA1 synapses, we used a mouse model $\left(\operatorname{TrkB}^{\mathrm{F} 616 \mathrm{~A}}\right)$ in which TrkB activity can be selectively inhibited by a chemical antagonist.

In contrast to many previous reports on juvenile/adult animals (for review, see Poo, 2001; Bramham and Messaoudi, 2005) (but see Huang et al., 2008), inhibition of TrkB signaling had no significant effect on the average level of potentiation within first 


\section{A control (naive input)}

facilitation
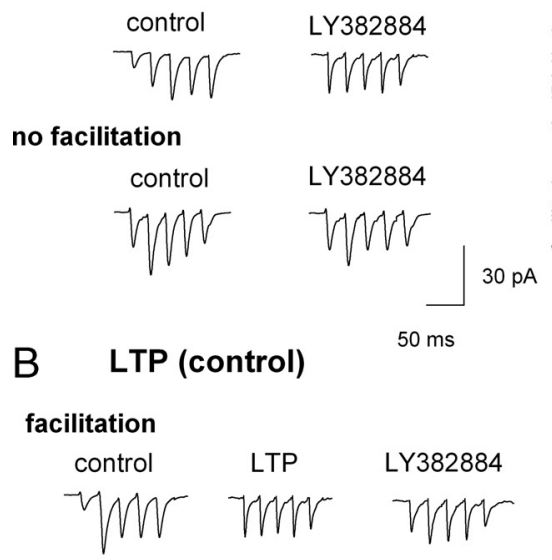

no facilitation

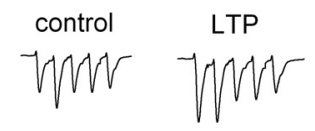

C LTP + 1NMPP1
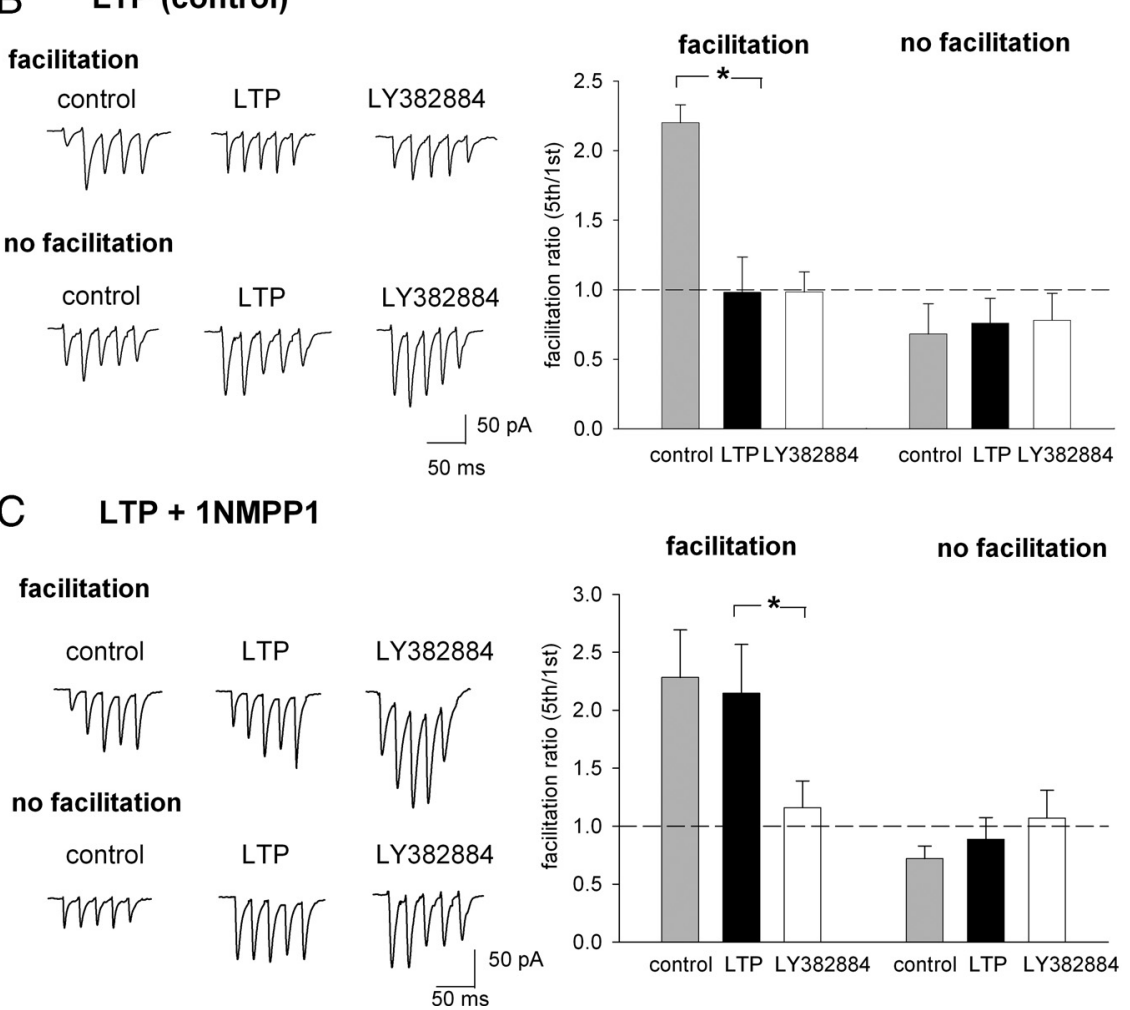

${ }_{50 \mathrm{~ms}} \mathrm{50}$
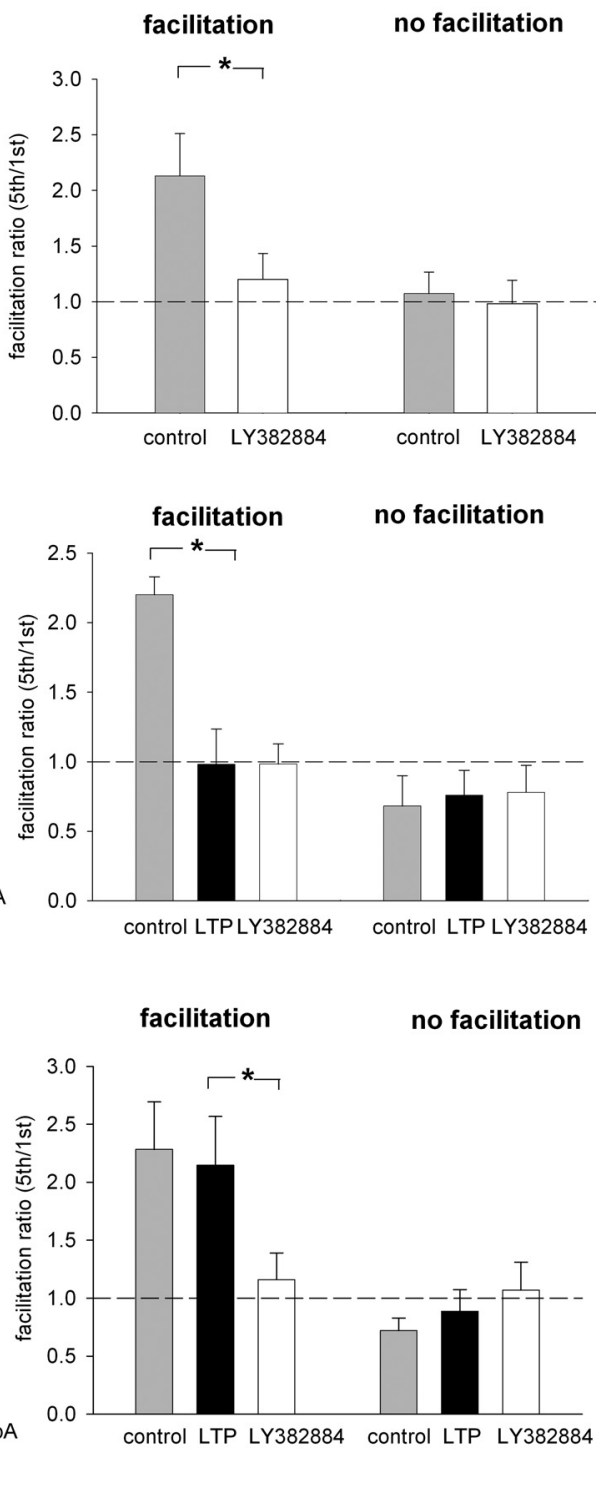

Figure 6. Acute inhibition of TrkB signaling prevents rapid changes in synapse dynamics and KAR activity in response to induction of LTP in the TrkB ${ }^{\mathrm{F} 616 \mathrm{~A}}$ mice (P4-P5). A, Example traces and pooled data showing the effect of LY382884 on EPSCS evoked at $50 \mathrm{~Hz}$ at naive inputs. LY382884 blocks synaptic facilitation and increases the amplitude of first EPSC at inputs that are initially facilitatory $(n=7)$ but has no effect on transmission at nonfacilitatory synapses $(n=5)$. B, Representative traces and pooled data showing the effect of pairing-induced LTP and consequent application of LY 382884 on EPSCs, evoked by $50 \mathrm{~Hz}$ afferent stimulation. LTP is associated with a complete loss of synaptic facilitation, and LY382884 has no effect on the synaptic facilitation after LTP induction (facilitatory, $n=9$; nonfacilitatory, $n=6$ ). ${ }^{*} p<0.05$. C, Corresponding data for experiments in which LTP was induced in the presence of 1NMPP1. On average, no change in synaptic facilitation was seen when LTP was induced in the presence of TrkB inhibiting 1NMPP1. Furthermore, the facilitation after LTP induction remained sensitive to inhibition by LY38824 (facilitatory, $n=9$; nonfacilitatory, $n=7) .{ }^{*} p<0.05$.

20 min after pairing at immature CA3-CA1 synapses. However, acute inhibition of TrkB completely blocked the presynaptic changes, including decrease in frequency-dependent facilitation of EPSCs as well as loss of endogenous KAR activity, that are associated with LTP at immature synapses with initially low $P_{\mathrm{r}}$ (Lauri et al., 2006). This suggests that, in young tissue, TrkB is not necessary for postsynaptic mechanisms underlying induction and early expression of pairing-induced synaptic potentiation, involving insertion and modified function of AMPA receptors at the postsynaptic density (Molnar and Isaac, 2002; Kerchner and Nicoll, 2008; Hanse et al., 2009). Rather, BDNF/TrkB appears critical for presynaptic plasticity at a stage of development when functional contact already exists but transmission is weak.

Interestingly, BDNF/TrkB signaling has been selectively associated with presynaptic LTP that can be induced by strong stimulation protocols at mature/ juvenile CA1 (Zakharenko et al., 2003). At this developmental stage, weak stimulation protocols of LTP induction, such as used in the present study, do not produce obvious presynaptic changes at CA3-CA1 synapses (Zakharenko et al., 2001) (M. Sallert, T. Taira, and S. Lauri, unpublished data). This suggests that the mechanism for rapid BDNF/TrkB-dependent presynaptic potentiation is prominent during early development, downregulated in parallel with maturation of the circuitry, but recapitulated in adult/juvenile synapses in response to certain strong stimulation patterns.

\section{Mechanism coupling BDNF-TrkB activation to KARs}

Regulation of KAR function in response to patterned activity inducing LTP or LTD has been shown in several areas of the brain. Thus, in addition to immature CA1, plasticity-associated changes in the function of synaptic KARs has been observed at the hippocampal mossy fibers (Lauri et al., 2001)-thalamocortical connections (Kidd and Isaac, 1999) and in the perirhinal cortex (Park et al., 2006). In cell culture, surface expression of KAR subunits is regulated by pharmacological activation of glutamate receptors, including KAR itself (Cho et al., 2003; Martin and Henley, 2004; Martin et al., 2007, 2008; Rivera et al., 2007). Both the surface expression as well as the postsynaptic KAR function is regulated by PKC (Cho et al., 2003; Hirbec et al., 2003; Martin and Henley, 2004; Park et al., 2006; Rivera et al., 2007). However, the corresponding presynaptic mechanisms are not known.

At the immature CA3-CA1 synapses, the activity-dependent changes in the synapse dynamics as well as in the KAR activity occur in the timescale of minutes (15-20 min) after pairing. The temporal window suggests that these TrkB-dependent changes are mediated by local presynaptic signaling cascades. BDNF binding to the TrkB receptor initiates distinct kinase pathways that could lead to parallel or sequential regulation of vesicle release machinery (Tyler et al., 2002) and KAR activity to efficiently enhance $P_{\mathrm{r}}$ at immature synapses. Long-term effects of BDNF involve changes in gene expression and are associated with structural alterations at presynaptic terminals (Tartaglia et al., 2001; Tyler and Pozzo-Miller, 2001; Bramham and Messaoudi, 2005); whether these processes involve additional changes in KAR targeting, function, and/or 
expression similar to what has been shown for postsynaptic AMPA- and NMDA-type glutamate receptors (Carvalho et al., 2008) is not known.

\section{Conclusions}

In conclusion, our data indicate that BDNF-TrkB signaling represents a potent mechanism that can couple neuronal activity to regulation of KAR function. This mechanism has immediate physiological relevance in controlling presynaptic maturation of CA3-CA1 synapses during early postnatal development. Furthermore, our data sheds light on how distinct activitydependent signals regulate each other to coordinate the effects of neuronal activity on presynaptic development.

\section{References}

Anderson WW, Collingridge GL (2007) Capabilities of the WinLTP data acquisition program extending beyond basic LTP experimental functions. J Neurosci Methods 162:346-356.

Berninger B, Schinder AF, Poo MM (1999) Synaptic reliability correlates with reduced susceptibility to synaptic potentiation by brain-derived neurotrophic factor. Learn Mem 6:232-242.

Bishop AC, Kung CY, Shah K, Witucki L, Shokat KM, Liu Y (1999) Generation of monospecific nanomolar tyrosine kinase inhibitors via a chemical genetic approach. J Am Chem Soc 121:627-631.

Bramham CR, Messaoudi E (2005) BDNF function in adult synaptic plasticity: the synaptic consolidation hypothesis. Prog Neurobiol 76:99-125.

Carvalho AL, Caldeira MV, Santos SD, Duarte CB (2008) Role of the brainderived neurotrophic factor at glutamatergic synapses. Br J Pharmacol 153:S310-S324.

Chen X, Ye H, Kuruvilla R, Ramanan N, Scangos KW, Zhang C, Johnson NM, England PM, Shokat KM, Ginty DD (2005) A chemical-genetic approach to studying neurotrophin signaling. Neuron 46:13-21.

Cho K, Francis JC, Hirbec H, Dev K, Brown MW, Henley JM, Bashir ZI (2003) Regulation of kainate receptors by protein kinase $\mathrm{C}$ and metabotropic glutamate receptors. J Physiol 548:723-730.

Collingridge GL, Isaac JT, Wang YT (2004) Receptor trafficking and synaptic plasticity. Nat Rev Neurosci 5:952-962.

Erickson JT, Conover JC, Borday V, Champagnat J, Barbacid M, Yancopoulos G, Katz DM (1996) Mice lacking brain-derived neurotrophic factor exhibit visceral sensory neuron losses distinct from mice lacking NT4 and display a severe developmental deficit in control of breathing. J Neurosci 16:5361-5371.

Ernfors P, Lee KF, Jaenisch R (1994) Mice lacking brain-derived neurotrophic factor develop with sensory deficits. Nature 368:147-150.

Feller MB (1999) Spontaneous correlated activity in developing neural circuits. Neuron 22:653-656.

Figurov A, Pozzo-Miller LD, Olafsson P, Wang T, Lu B (1996) Regulation of synaptic responses to high-frequency stimulation and LTP by neurotrophins in the hippocampus. Nature 381:706-709.

Gärtner A, Polnau DG, Staiger V, Sciarretta C, Minichiello L, Thoenen H, Bonhoeffer T, Korte M (2006) Hippocampal long-term potentiation is supported by presynaptic and postsynaptic tyrosine receptor kinase B-mediated phospholipase C gamma signaling. J Neurosci 26:3496-3504.

Gottschalk W, Pozzo-Miller LD, Figurov A, Lu B (1998) Presynaptic modulation of synaptic transmission and plasticity by brain-derived neurotrophic factor in the developing hippocampus. J Neurosci 18:6830-6839.

Hanefeld U, Rees CW, White AJ, Williams DJ (1996) One-pot synthesis of tetrasubstituted pyrazoles: proof of regiochemistry. J Chem Soc Perkin Trans 1:1545-1552.

Hanse E, Gustafsson B (2001) Factors explaining heterogenity in short-term synaptic dynamics of hippocampal glutamatergic synapses in the neonatal rat. J Physiol 537:141-149.

Hanse E, Taira T, Lauri S, Groc L (2009) Glutamate synapse in developing brain: an integrative perspective beyond the silent state. Trends Neurosci, in press.

Hirbec H, Francis JC, Lauri SE, Braithwaite SP, Coussen F, Mulle C, Dev KK, Coutinho V, Meyer G, Isaac JT, Collingridge GL, Henley JM, Couthino V (2003) Rapid and differential regulation of AMPA and kainate receptors at hippocampal mossy fibre synapses by PICK1 and GRIP. Neuron 37:625-638.
Huang YZ, Pan E, Xiong ZQ, McNamara JO (2008) Zinc-mediated transactivation of TrkB potentiates the hippocampal mossy fiber-CA3 pyramid synapse. Neuron 57:546-558.

Kerchner GA, Nicoll RA (2008) Silent synapses and the emergence of a postsynaptic mechanism for LTP. Nat Rev Neurosci 9:813-825.

Kidd FL, Isaac JT (1999) Developmental and activity-dependent regulation of kainate receptors at thalamocortical synapses. Nature 400:569-573.

Kramár EA, Lin B, Lin CY, Arai AC, Gall CM, Lynch G (2004) A novel mechanism for the facilitation of theta-induced long-term potentiation by brain-derived neurotrophic factor. J Neurosci 24:5151-5161.

Lauri SE, Bortolotto ZA, Bleakman D, Ornstein PL, Lodge D, Isaac JT, Collingridge GL (2001) A critical role of a facilitatory presynaptic kainate receptor in mossy fiber LTP. Neuron 32:697-709.

Lauri SE, Lamsa K, Pavlov I, Riekki R, Johnson BE, Molnar E, Rauvala H, Taira T (2003) Activity blockade increases the number of functional synapses in the hippocampus of newborn rats. Mol Cell Neurosci 22:107-117.

Lauri SE, Segerstråle M, Vesikansa A, Maingret F, Mulle C, Collingridge GL, Isaac JT, Taira T (2005) Endogenous activation of kainate receptors inhibits glutamatergic transmission and modulates network activity in the developing hippocampus. J Neurosci 25:4473-4484.

Lauri SE, Vesikansa A, Segerstråle M, Collingridge GL, Isaac JT, Taira T (2006) Functional maturation of CAl synapses involves activitydependent loss of tonic kainate receptor-mediated inhibition of glutamate release. Neuron 50:415-429.

Lessmann V, Heumann R (1998) Modulation of unitary glutamatergic synapses by neurotrophin- $4 / 5$ of brain-derived neurotrophic factor in hippocampal microcultures: presynaptic enhancement depends on preestablished paired-pulse facilitation. Neuroscience 86:399-413.

Martin S, Henley JM (2004) Activity-dependent endocytic sorting of kainate receptors to recycling or degradation pathways. EMBO J 23:4749-4759.

Martin S, Nishimune A, Mellor JR, Henley JM (2007) SUMOylation regulates kainate-receptor-mediated synaptic transmission. Nature 447:321-325.

Martin S, Bouschet T, Jenkins EL, Nishimune A, Henley JM (2008) Bidirectional regulation of kainate receptor surface expression in hippocampal neurons. J Biol Chem 283:36435-36440.

Mohajerani MH, Sivakumaran S, Zacchi P, Aguilera P, Cherubini E (2007) Correlated network activity enhances synaptic efficacy via BDNF and the ERK pathway at immature CA3 CA1 connections in the hippocampus. Proc Natl Acad Sci U S A 104:13176-13181.

Molnar E, Isaac JT (2002) Developmental and activity dependent regulation of ionotropic glutamate receptors at synapses. ScientificWorldJournal 2:27-47.

Palva JM, Lamsa K, Lauri SE, Rauvala H, Kaila K, Taira T (2000) Fast network oscillations in the newborn rat hippocampus in vitro. J Neurosci 20:1170-1178.

Park Y, Jo J, Isaac JT, Cho K (2006) Long-term depression of kainate receptor-mediated synaptic transmission. Neuron 49:95-106.

Pinheiro PS, Mulle C (2008) Presynaptic glutamate receptors: physiological functions and mechanisms of action. Nat Rev Neurosci 9:423-436.

Poo MM (2001) Neurotrophins as synaptic modulators. Nat Rev Neurosci 2:24-32.

Rantamäki T, Hendolin P, Kankaanpää A, Mijatovic J, Piepponen P, Domenici E, Chao MV, Männistö PT, Castrén E (2007) Pharmacologically diverse antidepressants rapidly activate brain-derived neurotrophic factor receptor TrkB and induce phospholipase-Cgamma signaling pathways in mouse brain. Neuropsychopharmacology 32:2152-2162.

Rivera R, Rozas JL, Lerma J (2007) PKC-dependent autoregulation of membrane kainate receptors. EMBO J 26:4359-4367.

Rose CR, Blum R, Kafitz KW, Kovalchuk Y, Konnerth A (2004) From modulator to mediator: rapid effects of BDNF on ion channels. Bioessays 26:1185-1194.

Sallert M, Malkki H, Segerstråle M, Taira T, Lauri SE (2007) Effects of the kainate receptor agonist ATPA on glutamatergic synaptic transmission and plasticity during early postnatal development. Neuropharmacology 52:1354-1365.

Shen W, Wu B, Zhang Z, Dou Y, Rao ZR, Chen YR, Duan S (2006) Activityinduced rapid synaptic maturation mediated by presynaptic cdc 42 signaling. Neuron 50:401-414.

Tartaglia N, Du J, Tyler WJ, Neale E, Pozzo-Miller L, Lu B (2001) Protein synthesis-dependent and independent regulation of hippocampal synapses by brain-derived neurotrophic factor. J Biol Chem 276:37585-37593. 
Tyler WJ, Pozzo-Miller LD (2001) BDNF enhances quantal neurotransmitter release and increases the number of docked vesicles at the active zones of hippocampal excitatory synapses. J Neurosci 21:42494258.

Tyler WJ, Perrett SP, Pozzo-Miller LD (2002) The role of neurotrophins in neurotransmitter release. Neuroscientist 8:524-531.

Tyler WJ, Zhang XL, Hartman K, Winterer J, Muller W, Stanton PK, PozzoMiller L (2006) BDNF increases release probability and the size of a rapidly recycling vesicle pool within rat hippocampal excitatory synapses. J Physiol 574:787-803.

Xu B, Gottschalk W, Chow A, Wilson RI, Schnell E, Zang K, Wang D, Nicoll RA, Lu B, Reichardt LF (2000) The role of brain-derived neurotrophic factor receptors in the mature hippocampus: modulation of long-term potentiation through a presynaptic mechanism involving TrkB. J Neurosci 20:6888-6897.

Zakharenko SS, Zablow L, Siegelbaum SA (2001) Visualization of changes in presynaptic function during long term synaptic plasticity. Nat Neurosci 4:711-717.

Zakharenko SS, Patterson SL, Dragatsis I, Zeitlin SO, Siegelbaum SA, Kandel ER, Morozov A (2003) Presynaptic BDNF required for a presynaptic but not postsynaptic component of LTP at hippocampal CA1-CA3 synapses. Neuron 39:975-990.

Zhang LI, Poo MM (2001) Electrical activity and development of neural circuits. Nat Neurosci 4:1207. 